\title{
Assessment of earth retaining wall sustainability: Value functions and stakeholder weighting sensitivity
}

\author{
I.P. Damians ${ }^{1,2}$, R.J. Bathurst ${ }^{3}$, A. Lloret ${ }^{1}$, A. Josa ${ }^{1}$, and D. El Mansouri ${ }^{2}$ \\ ${ }^{1}$ School of Civil Engineering, Universitat Politècnica de Catalunya - BarcelonaTech, Barcelona, Spain. \\ ${ }^{2}$ VSL International Ltd. VSL Technical Center Barcelona, Spain. \\ ${ }^{3}$ Royal Military College of Canada, Kingston, Ontario, Canada.
}

\begin{abstract}
Earth retaining walls are common geotechnical structures with a wide range of solutions available to perform the same function. More and more, geotechnical engineers are asked to find the best solution among several options in different civil engineering applications based on environmental impact, cost and societal/functional issues. Evaluation of these three pillars during the selection process of a structure (such as an earth retaining wall) is called a sustainability assessment. This paper describes a sustainability assessment methodology and gives examples to select the best sustainable option from candidate conventional gravity and cantilever wall types, and steel and polymeric soil reinforced mechanically stabilized earth (MSE) walls of $5 \mathrm{~m}$ height. Analyses were carried out using the MIVES methodology which is based on value theory and multi-attribute assumptions. The paper identifies how indicator issues are scored, weighted and aggregated to generate final numerical scores that allow solution options to be ranked. The final scores include an adjustment based on stakeholder preferences for the relative importance of the three sustainability pillars (environmental, economic (cost) and societal/functional). The analysis results show that MSE wall solutions are most often the best option in each category compared to conventional gravity and cantilever wall solutions and thus most often the final choice when scores from each pillar were aggregated to a final score. The paper also includes a sensitivity analysis of the choice of value functions and stakeholder weighting preferences on the final ranking scores used to select the best sustainable solution. The analyses also show that the choice of value function and stakeholder preferences can lead to a conventional structure being the best option.
\end{abstract}

\section{INTRODUCTION}

Sustainability and sustainable development relate to the capacity to carry out an activity (such as manufacturing or constructing a product) with minimal economic, societal and/or environmental impact (WCED 1987; Josa and Alavedra 2006). In civil engineering works, several construction solutions can satisfy the same functional requirements. Examples are pavements (asphalt, concrete...), bridges (simple beam, arch, cable-stayed, suspension...), foundations (shallow, deep...), etc. However, solutions will vary with respect to sustainability (i.e., different costs of materials, construction and maintenance, different environmental impact and societal effects). The adoption of sustainability criteria during the design of new projects is becoming more common in many countries, and these criteria are being used to influence decision making (Aguado et al. 2012). In the past, the final selected solution was typically based on a compromise between minimum costs and maximum functionality. Today, an appropriate sustainability analysis approach is often recommended so that 
environmental and social impacts are part of the solution decision process. From a total sustainability point of view there are three pillars or requirements: environmental, economic and societal that can be assessed from "cradle to grave" (though in some situations "cradle to gate" or "cradle to operational" is more realistic). A proper balance between these criteria is required for sustainable development or solution selection (Josa and Alavedra 2006; Josa et al. 2008).

Earth retaining walls are very common in civil engineering works with wellestablished design procedures for typical structures. Nevertheless, there are a wide range of solutions within any wall classification and between different wall solution classifications (e.g., conventional gravity, cantilever or mechanically stabilized earth (MSE) walls). A discussion of the advantages and limitations of different types of earth retaining wall solutions can be found in guidance documents and in papers such as Jones (2002) and Damians et al. (2017, 2018).

Sustainability is a young discipline, and a consensus on a formal set of rules is not available, particularly in civil engineering. Different models continue to be developed or refined. This paper uses the case of earth retaining wall structures to make choices between wall options based on a sustainability perspective (Damians et al. 2018) including sensitivity analyses on value function types and stakeholder preferences. The paper identifies the information that is required to exercise rational decision making for these types of structures within a sustainability assessment framework.

\section{METHODOLOGY}

\section{Sustainability model: MIVES tool}

There is no unique way to quantify sustainability. Therefore, a comparison methodology is required with application-specific sustainability models. As a starting point, it is necessary to identify the same functional unit (FU). This unit defines what precisely is being studied and provides a reference for the inputs and outputs that enable the alternatives to be compared and analyzed. A sustainability model assessment based on value-theory and multi-attribute assumptions called MIVES (Value Integrated Model for Sustainable Evaluations; Josa et al. 2008) was adopted in this investigation to evaluate the sustainability of each case study. Each sustainability requirement (i.e., environmental, economic, societal/functional) can be defined by one or more criteria and a set of quantifiable indicators. The set of requirements, criteria and indicators define a decision-making tree for multi-criteria analysis. In other models, additional criteria levels are possible, but in this investigation a simple approach was adopted. The indicators are defined by value-functions which can have different forms (i.e., linear, concave, convex, S-shape; see Alarcon et al. 2011). The value-functions allow the transformation from indicator-units (e.g., physical units) to common dimensionless value units. Next, the related criteria and indicators are defined globally by weighting and aggregation procedures. The final result is an overall single index value (final score) for each proposed alternative. This process is a powerful tool when an objective decision is needed (i.e., as opposed to a purely 
subjective decision), and allows the weaknesses and strengths of each proposal to be assessed. Strategies to analyze the three pillars of sustainable development are briefly explained below.

The environmental pillar can be defined using specific indicators applicable to each study case. A powerful but sometimes difficult approach is to develop a life cycle assessment (LCA) for each case as demonstrated in the current investigation. A LCA must consider all the associated environmental aspects and impacts of any construction process and material used in a structure (ISO 2006). Midpoint (Mp) indicators (such as tons of equivalent carbon dioxide, $\mathrm{CO}_{2} \mathrm{e}$, and intermediate effects representing quantity of pollutants) and Endpoint (Ep) indicators (based on damage models which are more understandable but also more complex) are typically used in LCA. There is scientific agreement with regard to the environmental impacts (obtained from LCA) in vectorized profiles. It is possible to use methods that include socio-political preference factors, internally weigh the impacts, and give a single-final score from LCA. The economic pillar mainly comes from project budgets, including materials and process costs, and can also include maintenance and dismantling costs. Social/functional indicators (e.g., resistance to fire, safety against climatic agents or even aesthetic considerations) may be difficult to choose or define. A typically good solution to quantify these indicators is to perform opinion surveys on professionals in the same knowledge field and then process the results and weigh the solutions through hierarchy processes such as AHP techniques (Saaty 2008), among other procedures. All these criteria and indicators can be evaluated deterministically or probabilistically using the MIVES tool.

\section{Case studies and design criteria}

The case studies selected in the current investigation are taken from Damians et al. (2017, 2018) representing four different earth retaining wall structure types ranging from conventional to modern in the order of gravity, cantilever, and mechanically stabilized earth (MSE) walls (Figure 1). These solutions vary widely with respect to material quantities and type, construction method, structural behavior, and performance. Each solution includes different design calculations. Although not considered in this investigation, there are hybrid design solutions available as well. The gravity wall solution is a concrete structure with geometry selected to satisfy external stability modes of failure. The cantilever wall represents a (steel rebar) reinforced concrete structure with much less concrete material (but higher quality). The MSE wall alternatives use reinforced soil behind a thin concrete panel facing. In one case the soil reinforcement is polymeric geogrid and in the other it is steel grid. The geogrid strength and steel grid bar diameter vary with layer depth below the wall crest in accordance with current accepted design procedures which are based on variants of active wedge theory. A functional unit (FU) was defined for each one meter-width of wall face and assuming a wall height of $5 \mathrm{~m}$, horizontal back slope and design life of 100 years. The soil was considered to be dry, granular (non-cohesive), with a unit weight of $20 \mathrm{kN} / \mathrm{m}^{3}$, friction angle of $30^{\circ}$ for the retained backfill and foundation, and $34^{\circ}$ for the reinforced backfill in MSE wall cases. The four proposed 
solutions were designed to minimize construction material quantities while achieving minimum acceptable margins of safety against internal and external modes of failure as recommended in AASHTO (2012) and ACI (2002) design codes.

The geometrical dimensions and structural details for all wall solutions are presented in Figure 1. The required materials, time and transportation inventory for the case study $(H=5 \mathrm{~m})$ are shown in Table 1 . The system boundaries and material quantities in each alternative have been framed by the system unit definition and determined by each design criteria and also taking into account all aspects related to material transport and construction works. Detailed information for other wall heights can be found in Damians et al. $(2017,2018)$.

\section{SUSTAINABLITY MODEL FOR EARTH RETAINING WALLS}

\section{General requirements (pillars), stakeholder scenarios and value functions}

The simplified decision-making tree flow-chart generated in this investigation is presented in Figure 2 (Damians et al. 2018). Different weighting multiplier combinations were applied to each sustainability pillar according to different hypothetical stakeholder group scenarios (see Table 2). Single criteria and indicator levels were also considered for each requirement category or pillar.

As shown in Figure 2, the value functions allow the transformation from indicator units to common dimensionless value units from 0 to 1 . A value function having the exponential decay formulation is available in the MIVES software toolkit, allowing different shapes to be captured by selection of different parameters (Alarcón et al. 2011). In the current study, sensitivity analyses were carried out assuming three different shapes of the value functions to transform the indicators for the environmental and economic pillars: convex, S-shape and linear (see Figure 3). The non-linear functions (convex and S-shape types) favor best solutions and discriminate against relatively poor solutions. For the $\mathrm{S}$-shape function, indicator entry units close to the "best" alternative returns the most favorable value (i.e., $V_{\text {indicator }}=1$ ). This is a way to identify the group of best alternatives, not just a single option. Table 3 presents the summary of all cases analyzed in this study according to the combinations of value function types considered for each pillar of sustainability.

\section{Environmental requirement}

SimaPro software (Pré Consultants bv 2010) was used to perform the LCA. The Ecoinvent v3.1 database and ReCiPe (ReCiPe 2014) method in the SimaPro software package was used to compute final scores (i.e., simplified Midpoint and Endpoint indicators). Ep indicators, related to the expected impact on human health, ecosystems, and natural resources were selected. Complete analysis and full details of the case studies are provided in Damians et al. (2017). A decreasing convex/Sshape/linear value function for the Ep final score was used over the [1,0] range; thus high LCA Endpoint values in Figure 3a translate to low value function multipliers 
(i.e., the higher the value, the less environmentally friendly the solution option). In the current study, two additional constraints on value function outcomes were imposed: Endpoint values that were twice the average value of all four solution alternatives for the given wall height case $(H=5 \mathrm{~m})$ were assigned a score of zero, and endpoint values with a score less than $50 \%$ of the average of all solutions were assigned a value of 1 . This strategy was used to ensure that obvious low environmental-impact cases were assigned a maximum value and solutions with very high environmental impact with respect to the other solutions were not rewarded with a non-zero value. As noted earlier, both indicator- and criterion-level weighting factors were assigned a value of 1 in the current study.

\section{Economic requirement}

With regard to the major material quantities for each wall type in Figure 1, an economic wall construction inventory was developed. ITEC-BEDEC (ITEC 2014) was the reference database adopted together with representative project material costs. Some construction costs were adjusted to better match actual market conditions. For example, for most of the components, the economic database already includes typical transportation and installation costs, and not only manufacturing costs. In MSE wall cases, facing panels and selected backfill transportation distances were taken to be 100 $\mathrm{km}$ and $10 \mathrm{~km}$, respectively. Variability of common material quantities and costing processes were considered by using a representative range of costs for the construction of each alternative (detailed explanation can be found in Damians et al. 2018). After applying these cost variation assumptions for all material components and related processes, the density function of risk quantification in terms of a triangular frequency distribution function for each wall was obtained and then used to generate random cost values for a wall solution using Monte Carlo simulation. Each random cost variable was converted to an indicator value by using the economic requirement value function (transformation) explained previously (see Figure 3b). The result is an array of random $V_{\text {indicator }}$ values between 1 and 0 . With this probabilistic scoring process from the economic budgets, high and low boundary values can be obtained with respect to the mode-price value, and a probabilistic average value deduced to obtain the final economic score of each alternative studied. The mode value of this array of random values was taken as $V_{\text {indicator }}$ for the economic level in the sustainability assessment flow chart in Figure 2.

Similar types of value functions as the ones used in the environmental level analyses were used for the economic value function and for the same reasons (Figure 3b) (i.e., reward low-cost solutions and discourage high-cost solutions). A value of 1 was assigned to the minimum possible cost of all solution options. Maximum cost outcomes that were more than $50 \%$ of the mode value of the cheapest solution were assigned a value of 1 . Since criteria and requirement weighting factors were taken as 1 in this study, then $V_{\text {final }}=V_{\text {requirement }}=V_{\text {indicator }}$.

\section{Societal/functional requirement}

To quantify the social impact requirement, it was important to identify the main civil 
engineering concerns with respect to the candidate earth retaining wall alternatives. To accomplish this, an opinion survey was conducted and compiled from 200 undergraduate Civil/Construction Engineering students and 50 graduate students enrolled in Geotechnical Engineering design classes at the Universitat Politècnica de Catalunya (UPC-BarcelonaTech). The survey results were used to identify and weight the general concerns for each retaining wall structure option. Relevant criteria and indicators were thus obtained. All the indicators were filtered and then evaluated by specialized professionals to ensure that all alternative wall solutions satisfy the same functional requirements. The average of the scores for each of the three survey populations was computed, and then a final $V_{\text {requirement }}$ score was assigned to each wall type by weighting the score for each group according to $20 \%$ for undergraduate students, $30 \%$ for graduate students and $50 \%$ for the experts. This procedure enabled a direct weighting of indicators and criteria that was judged sufficient for this simplified example. The value function that appeared in this string of calculations was linear for all cases in this study, with a score of 1 transformed to 0 and a score of 5 transformed to 1 . Weighting values for indicator and criteria items were deduced from survey results described in the next section. The calculation of $V_{\text {requirement }}$ for the societal/ function level follows the flow path shown in Figure 2. The value function that appeared in this string of calculations was fixed as linear $(L)$ in all cases analyzed in the current study, with a score of 1 transformed to 0 and a score of 5 transformed to 1 . Weighting values for indicator and criteria items were deduced from survey results and are described next.

\section{SUSTAINABILITY ASSESSMENT RESULTS}

Figure 4 shows the environmental Midpoint (Mp) indicators for the global warning potential (tones of $\mathrm{CO}_{2} \mathrm{e}$ ) and cumulative energy demand (GJ) obtained for the defined functional unit for the case studies (i.e., 5 m-high earth retaining wall structures). The results obtained from the single-final score using Endpoint (Ep) model indicators analysis are identified in Figure 5. The amount of material and the different environmental \%-effect of each component $(\geq 3 \%)$ are shown in each component breakdown for each wall alternative. The results show that the MSE wall options resulted in better Mp and Ep values, with similar trends/differences obtained between alternatives for $H=5 \mathrm{~m}$-high structures. Additional results from the LCA have been reported by Damians et al. (2017).

The results for the economic pillar (requirement) analyses are presented in Figure 6. Construction work sequence and construction work type have been selected and are included in the results. Figure 6 also includes the computed cost ranges for each alternative according to the total minimum, maximum and mode cost values. The differences between the maximum and minimum \%-values influences the resultant value transformation from the value function shape selected through the probabilistic process.

Table 4 presents the criteria, indicators and weightings used in the societal pillar analysis. Again, the MSE wall solutions are judged best, although traditional solutions 
have an advantage in about half of the criteria categories. The table shows that the weighting assigned to each indicator is critical to optimal solution outcomes.

The final pillars and MIVES scores are presented in Figure 7 and Figure 8, according to the stakeholder group and related sustainability pillar weighting scenario assumed (see Table 2). It can be observed that using the proposed model and methodology, the MSE wall with polymeric-geogrid reinforcement gives the highest (best) rating for sustainability assessment in almost all stakeholder group scenarios and value function decay shapes considered in this investigation. If environmental issues are the most important concern of stakeholders, then the MSE solutions are the best solution by a substantial margin (see Figure 7b). However, for pillar weighting scenario C (i.e., economic stakeholder group) conventional wall alternatives become viable and cantilever walls are the best alternative if the $\mathrm{S}$-shape value function is used to convert costs to indicator values (see Figure 8a).

\section{CONCLUSIONS}

Sustainability assessment is becoming a key requirement for selection of the best solution in civil engineering works. This paper presents a simplified but promising approach for sustainability assessment. The model is based on the MIVES methodology using value theory and multi-attribute assumptions. The general approach is applied to four different $5 \mathrm{~m}$-high earth retaining walls that perform the same function.

The analysis results show that MSE wall solutions are most often the best option in each sustainability pillar category (environmental, economic and societal/functional) compared to conventional gravity and cantilever wall solutions, and thus most often the best final choice when scores from each pillar were aggregated to a final score. Nevertheless, different scenarios are presented with regard to stakeholder preferences for the relative importance of the three sustainability pillars. When cost is weighted most highly of the three pillars, then the conventional wall solutions give best MIVES score for walls of 5-m height. In this scenario, the cantilever wall alternative gives the highest (best) score if the S-shape value function is selected to assess the economic pillar. If environmental issues are the most important concern of stakeholders, then the MSE wall solutions are the best solution by a substantial margin. The MSE wall solutions were shown to be the best type of structure based on the MIVES methodology mainly because a large volume of the structure is comprised of soil rather than concrete and reinforcement steel. 


\section{REFERENCES}

Aguado, A. del Caño, A. de la Cruz, Ma P. Gómez, D. \& Josa, A. (2012). Sustainability assessment of concrete structures within the Spanish structural concrete code. ASCE Journal of Construction Engineering Management 138(2), 268-276.

Alarcón, B. Aguado, A. Manga, R. and Josa, A. (2011). A value function for assessing sustainability: Application to industrial buildings, Sustainability 3, 35-50.

AASHTO (2016). AASHTO LRFD Bridge Design Specifications (6 ${ }^{\text {th }}$ edition), American Association of State Highway and Transportation Officials, Washington, DC.

ACI Committee 318 (2002). Building Code Requirements for Structural Concrete (ACI 318-02) and Commentary (318R-02), American Concrete Institute, Farmington, MI.

Damians, I.P., Bathurst, R.J Adroguer E., Josa, A., and Lloret, A. (2017). Environmental assessment of earth retaining wall structures. ICE Environmental Geotechnics. 10.1680/jenge.15.00040.

Damians, I.P., Bathurst, R.J Adroguer E., Josa, A., and Lloret, A. (2018). Sustainability assessment of earth retaining wall structures. ICE Environmental Geotechnics. 10.1680/jenge.16.00004.

ISO (2006). Environmental management, Life Cycle Assessment, Principles and Framework (ISO 14000:2006). International Organization for Standardization, Geneva.

ITEC (2014). Banco estructurado de datos de elementos constructivos (BEDEC), Foundation Catalonia Institute of Construction Technology, Barcelona. $<$ http://www.itec.es/home/index.asp>

Jones C.J.F.P. (2002). Guide to Reinforced Fill Structure and Slope Design (Geoguide 6), Geotechnical Engineering Office, Civil Engineering Department, Hong Kong.

Josa, A. San José, T. and Cuadrado, J. (2008). El caso de la EHE. Jornada sobre Sostenibilidad en la tecnología del hormigón: MI-VES, una herramienta de apoyo a la toma de decisiones, 84-95. Department of Construction Engineering, UPCBarcelonaTech, Barcelona.

Josa, A. and Alavedra, P. (2006). El concepto de sostenibilidad. La medida de la sostenibilidad en edificación industrial: MIVES (Eds: Losada, R. Rojí, E. and Cuadrado, J.), 59-70. UPV, UPC, Labein-Tecnalia, Bilbao.

Pré Consultants bv. (2010). SimaPro software, v.8. Amersfoort.

ReCiPe (2014). ReCiPe. <http://www.lcia-recipe.net/>

Saaty, T. (2008). Decision making with the analytic hierarchy process. International Journal of Services Sciences 1, 83-98.

WCED (1987). Our common future, Report of the World Commission on Environment and Development, The Brundtland Commission, United Nations Documents, NGO Committee on Education, Oxford University Press, Oxford. 
Table 1. Materials, time and transportation inventory for $H=5 \mathrm{~m}$ wall case.

\begin{tabular}{|c|c|c|c|c|c|}
\hline \multirow[b]{2}{*}{ Category } & \multirow[b]{2}{*}{$\begin{array}{l}\text { Related items and } \\
\text { components }\end{array}$} & \multirow[b]{2}{*}{ Units } & \multicolumn{3}{|c|}{ Wall type: } \\
\hline & & & Gravity & Cantilever & $\begin{array}{c}\text { MSE wall: } \\
\text { Steel \& } \\
\text { Polymeric }\end{array}$ \\
\hline \multirow{4}{*}{$\begin{array}{c}\text { Structural } \\
\text { materials }\end{array}$} & Concrete & $\mathrm{m}^{3}$ & 6.7 & 2.3 & 0.05 \\
\hline & Rebar & tones & N/A & 0.27 & N/A \\
\hline & Precast panels & $\mathrm{m}^{2}$ & N/A & N/A & 5.6 \\
\hline & Soil reinforcement & $\mathrm{Kg}$ & N/A & N/A & $\begin{array}{c}54 \text { (steel grid) } \\
10 \text { (geogrid) }\end{array}$ \\
\hline Soil materials & $\begin{array}{l}\text { Backfill (reinforced } \\
\text { and/or retained) }\end{array}$ & tones & 23.3 & 35.9 & 61.8 \\
\hline \multirow[t]{2}{*}{ Earthworks } & Excavation & $\mathrm{m}^{3}$ & 1.2 & 0.9 & 3.9 \\
\hline & $\begin{array}{l}\text { Backfilling and } \\
\text { compaction time }\end{array}$ & $\mathrm{h}$ & 1500 & 2800 & 9200 \\
\hline \multirow[t]{3}{*}{ Transportation } & Concrete (and steel) & $\mathrm{km}$ & 10 & 10 & N/A \\
\hline & $\begin{array}{l}\text { Panels and } \\
\text { reinforcement }\end{array}$ & $\mathrm{km}$ & N/A & N/A & 100 \\
\hline & Selected backfill & $\mathrm{km}$ & N/A & N/A & 10 \\
\hline
\end{tabular}

Table 2. Requirement weighting scenarios considered.

\begin{tabular}{|c|c|c|c|}
\hline \multirow{2}{*}{$\begin{array}{c}\text { Stakeholder } \\
\text { group/pillar } \\
\text { weighting scenario }\end{array}$} & \multicolumn{3}{|c|}{ Weightings for requirement levels (pillars): $\boldsymbol{W}_{\text {requirement }}$} \\
\cline { 2 - 4 } & Environmental & Economic & Societal and functional \\
\hline $\mathrm{A}$ & $1 / 3$ & $1 / 3$ & $1 / 3$ \\
\hline $\mathrm{B}$ & $\mathbf{2 / 3}$ & $1 / 6$ & $1 / 6$ \\
\hline $\mathrm{C}$ & $1 / 6$ & $\mathbf{2 / 3}$ & $1 / 6$ \\
\hline $\mathrm{D}$ & $1 / 6$ & $1 / 6$ & $\mathbf{2 / 3}$ \\
\hline
\end{tabular}


Table 3. Summary of cases analyzed according to the combinations of value function types considered. C: Convex, S: S-shape, L: Linear (see Figure 3).

\begin{tabular}{|c|c|c|c|}
\hline \multirow{2}{*}{$\begin{array}{c}\text { Case: } \\
\text { Nomenclature }\end{array}$} & \multicolumn{3}{|c|}{ Value function type for requirement levels (pillars) } \\
\hline & Environmental & Economic & Societal and functional \\
\hline $1: \mathrm{CCL}$ & \multirow{3}{*}{ Convex } & Convex & \multirow{9}{*}{ Linear } \\
\hline 2: CSL & & S-Shape & \\
\hline 3: CLL & & Linear & \\
\hline 4: SCL & \multirow{3}{*}{ S-Shape } & Convex & \\
\hline 5: SSL & & S-Shape & \\
\hline 6: SLL & & Linear & \\
\hline 7: LCL & \multirow{3}{*}{ Linear } & Convex & \\
\hline 8: LSL & & S-Shape & \\
\hline 9: LLL & & Linear & \\
\hline
\end{tabular}


Table 4. Societal and functional criteria and indicators: survey form results (Damians et al. 2018).

\begin{tabular}{|c|c|c|c|c|c|}
\hline \multirow[b]{2}{*}{$\begin{array}{l}\text { Criteria } \\
\text { (\& weightings) }\end{array}$} & \multirow[b]{2}{*}{$\begin{array}{l}\text { Indicators }{ }^{(a)} \\
\text { (\& weightings) }^{\text {\& weight }}\end{array}$} & \multicolumn{4}{|c|}{ Wall type: } \\
\hline & & Gravity & Cantilever & $\begin{array}{l}\text { MSE } \\
\text { wall: } \\
\text { Steel }\end{array}$ & $\begin{array}{c}\text { MSE } \\
\text { wall: } \\
\text { Polymeric }\end{array}$ \\
\hline \multirow{5}{*}{$\begin{array}{l}\text { Marketing } \\
\text { considerations } \\
(25 \%)\end{array}$} & $1(25 \%)$ & $* * * *$ & $* * * * *$ & $* * *$ & $* *$ \\
\hline & $2(15 \%)$ & $* * * * *$ & $* * * *$ & $* * *$ & $* * *$ \\
\hline & $3(10 \%)$ & $*$ & $*$ & $* * * *$ & $* * * * *$ \\
\hline & $4(25 \%)$ & $* * * * *$ & $* * * * *$ & $* *$ & $* * *$ \\
\hline & $5(15 \%)$ & $*$ & $*$ & $* * * *$ & $* * *$ \\
\hline \multirow{5}{*}{$\begin{array}{l}\text { Design and } \\
\text { construction } \\
\text { methodology } \\
(25 \%)\end{array}$} & $6(10 \%)$ & $* * * *$ & $* * * *$ & $* * *$ & $* * *$ \\
\hline & $7(20 \%)$ & $* * * * *$ & $* * *$ & $* * *$ & $* *$ \\
\hline & $8(25 \%)$ & $* * *$ & $* * *$ & $* * *$ & $* * *$ \\
\hline & $9(30 \%)$ & $* *$ & $* *$ & $* * * *$ & $* * * * *$ \\
\hline & $10(25 \%)$ & $* *$ & $* *$ & $* * *$ & $* * * *$ \\
\hline \multirow[t]{2}{*}{ Aesthetics (15\%) } & $11(100 \%)$ & $* *$ & $* * *$ & $* * * *$ & $* * * *$ \\
\hline & $12(25 \%)$ & $* *$ & $* *$ & $* * *$ & $* * *$ \\
\hline \multirow{3}{*}{$\begin{array}{l}\text { Reliability } \\
(20 \%)\end{array}$} & $13(25 \%)$ & $* * * * *$ & $* * * * *$ & $* * *$ & $* * *$ \\
\hline & $14(25 \%)$ & $* * * * *$ & $* * * *$ & $* * *$ & $* * *$ \\
\hline & $15(25 \%)$ & $* *$ & $* *$ & $* * *$ & $* * *$ \\
\hline \multirow{2}{*}{$\begin{array}{l}\text { Resilience } \\
(15 \%)\end{array}$} & $16(50 \%)$ & $* *$ & $*$ & $* *$ & $* *$ \\
\hline & $17(50 \%)$ & $* *$ & $* *$ & $* * *$ & $* * * *$ \\
\hline
\end{tabular}

(a) Indicator numbers: 1-Acceptance of wall type; 2-Labour requirements (less is better); 3-Research and development required (more is better); 4-Use of local materials and technology (more is better); 5-Specialist/trained workers required (more is better); 6-Land use (less is better); 7-Ease of design; 8-Safety during construction; 9-Ease of construction; 10-Duration of construction; 11-Aesthetics; 12-Ease of repair (more is better); 13-Ease of routine maintenance (more is better); 14-Expectation of satisfactory performance; 15-Consequences of poor performance requiring repair (low is better); 16-Flexibility to design changes during construction; 17-Robustness against site conditions changes from design specifications (e.g., water). 
a)

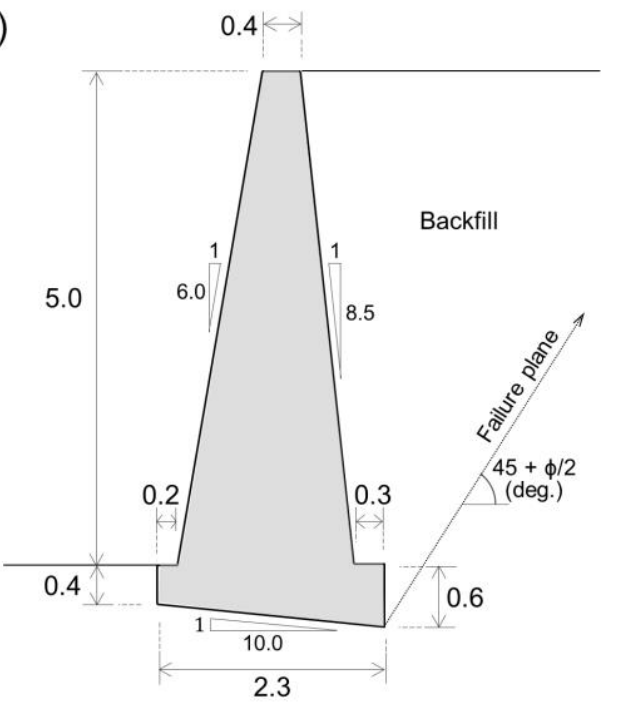

b) $\quad 0.25$

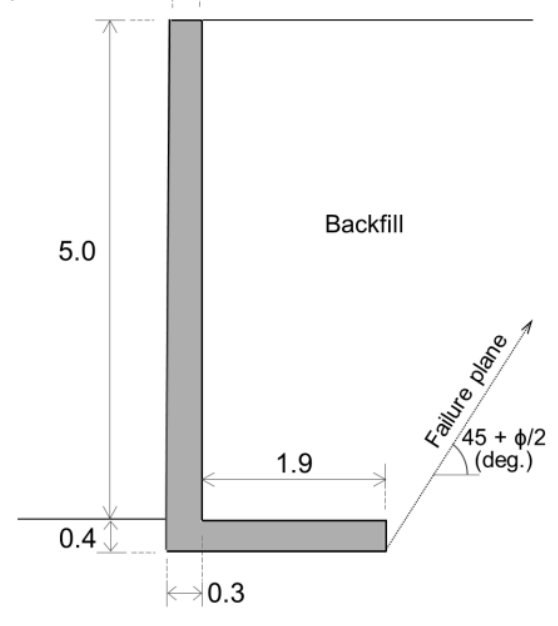

c)

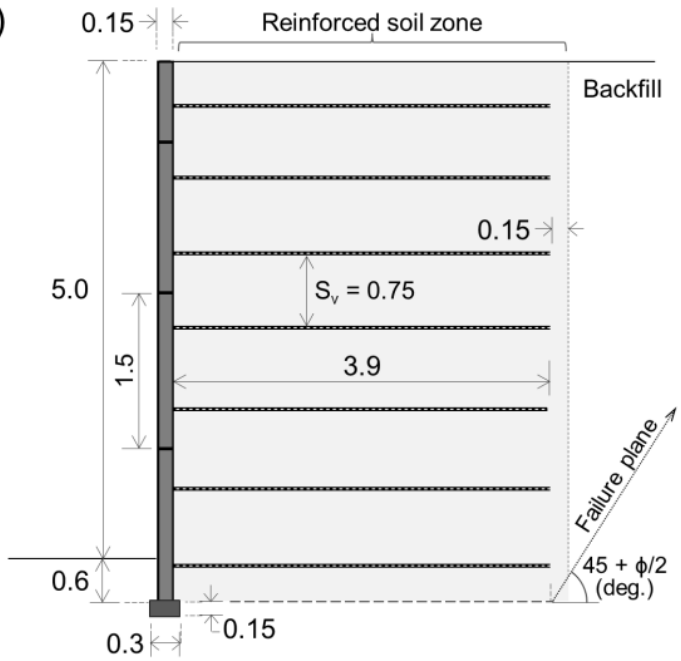

Figure 1. Geometry for (a) gravity, (b) cantilever and (c) MSE walls with steel or polymeric soil reinforcement. All dimensions in metres. 


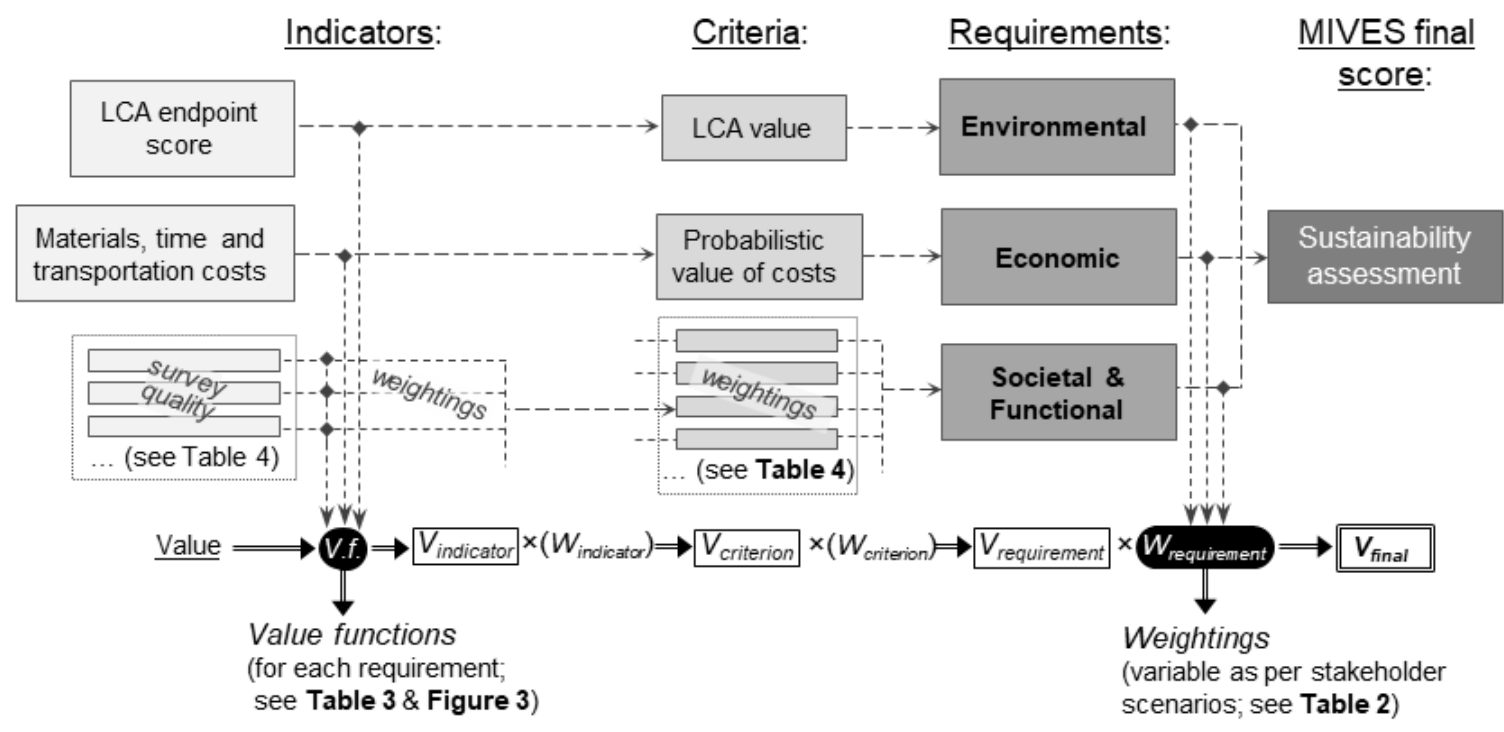

Figure 2. Sustainability assessment flow chart (Damians et al. 2018). 
a)

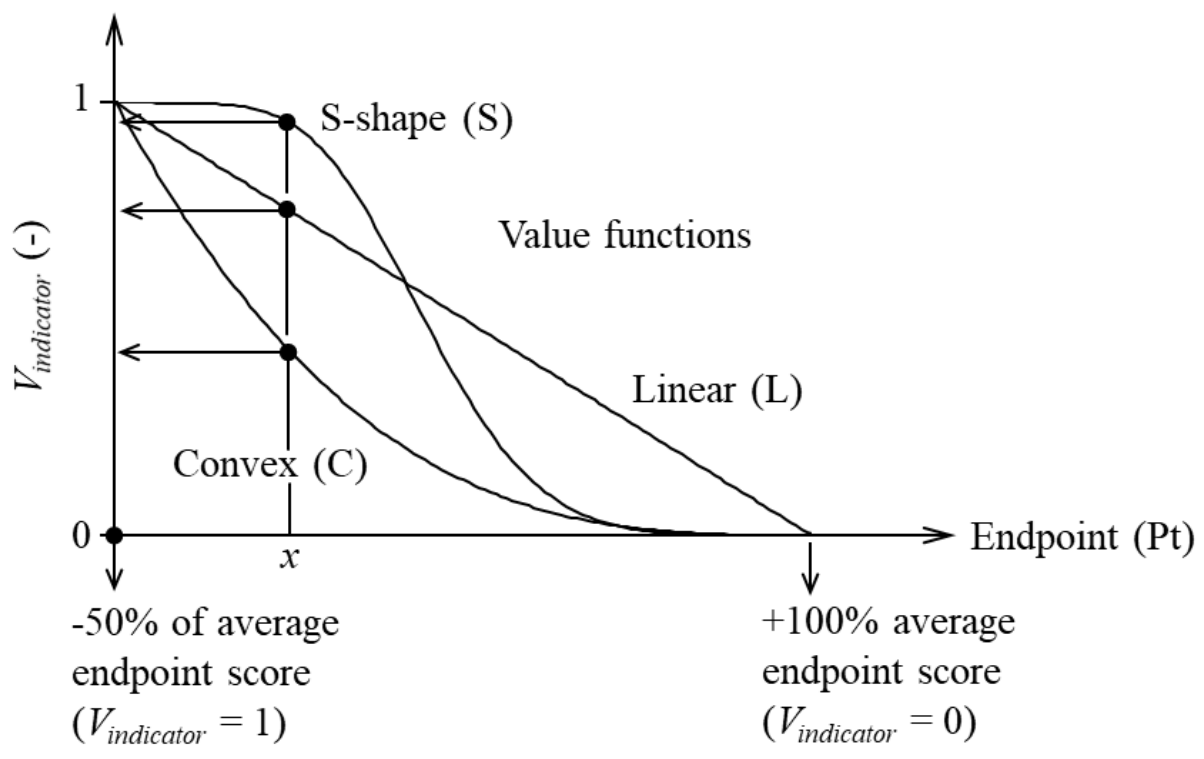

b)

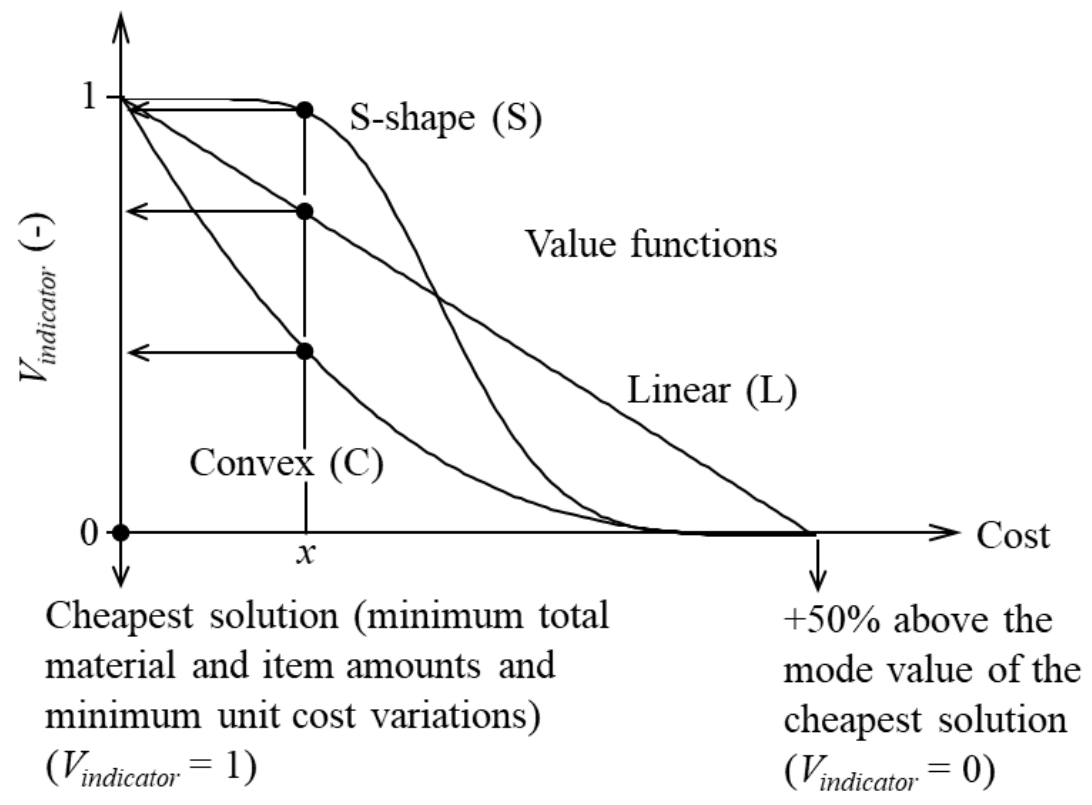

Figure 3. Value functions assumed and limits for (a) environmental and (b) economic level analyses. 
a) GWP

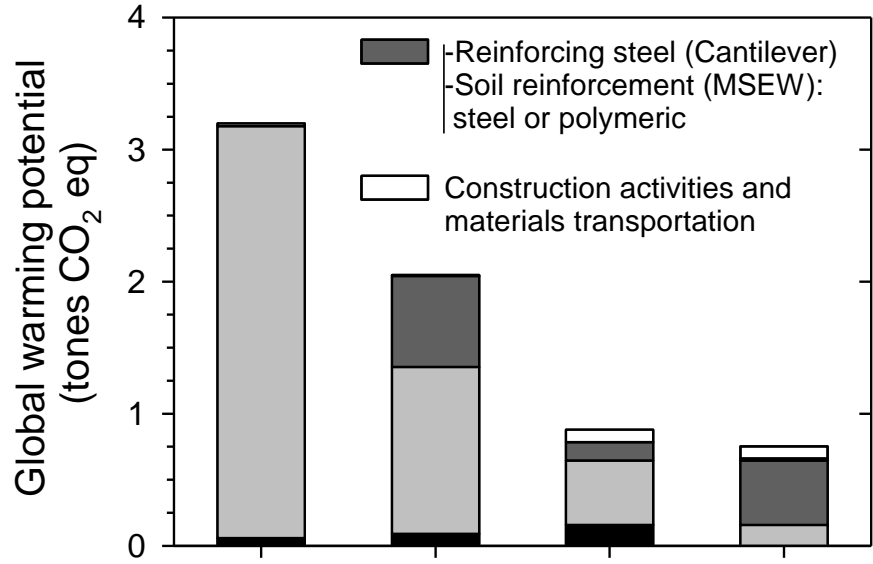

b) CED

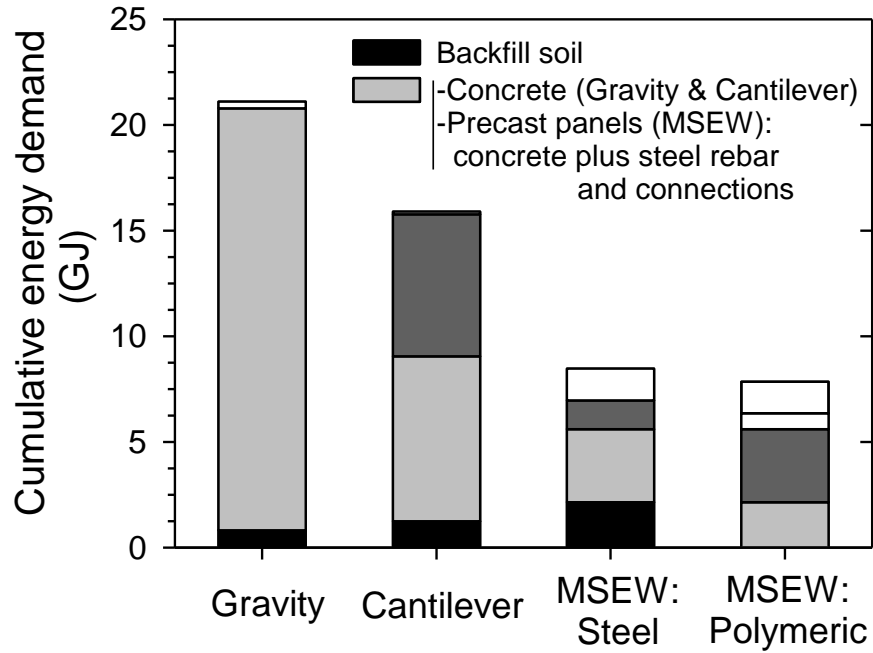

Figure 4. Midpoint single score results: (a) Global warning potential and (b) Cumulative energy demand.

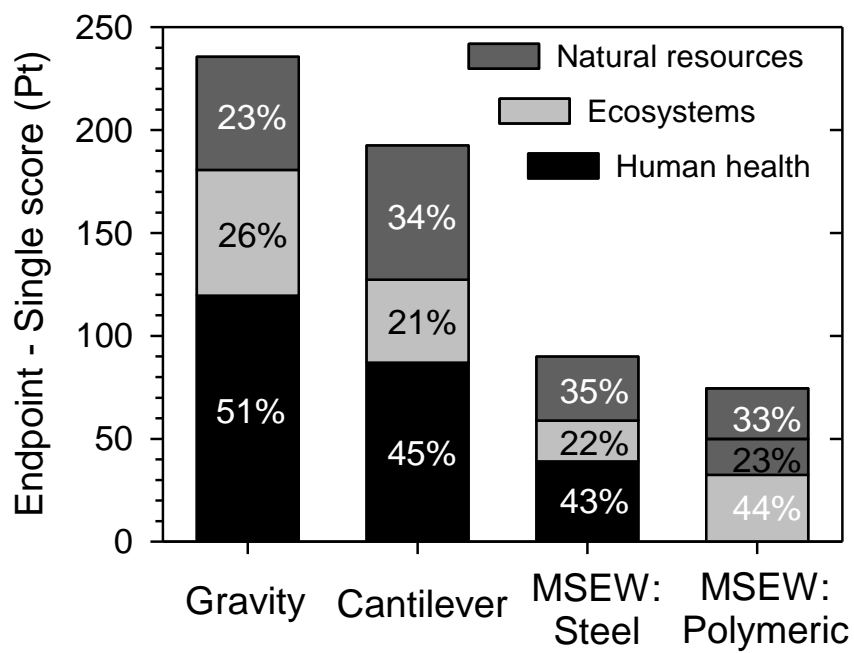

Figure 5. Endpoint single score results and contributions. 
La: Labour; Ce: Construction equipment; Mt: Materials; Tr: Transport

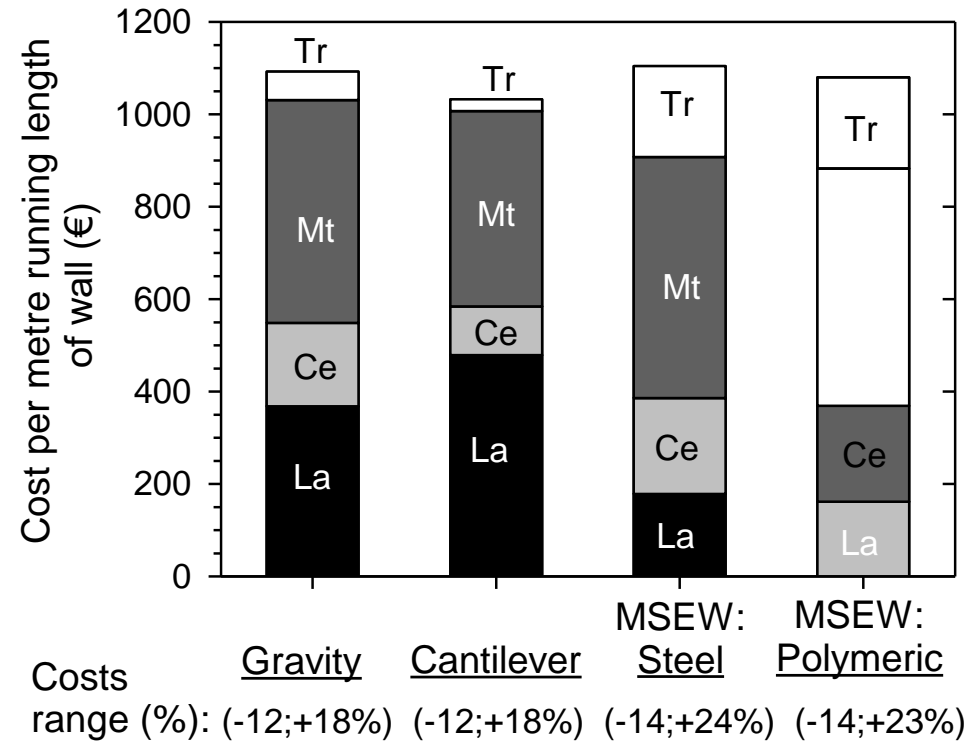

Figure 6. Economic inventory using mode prices. 
a)
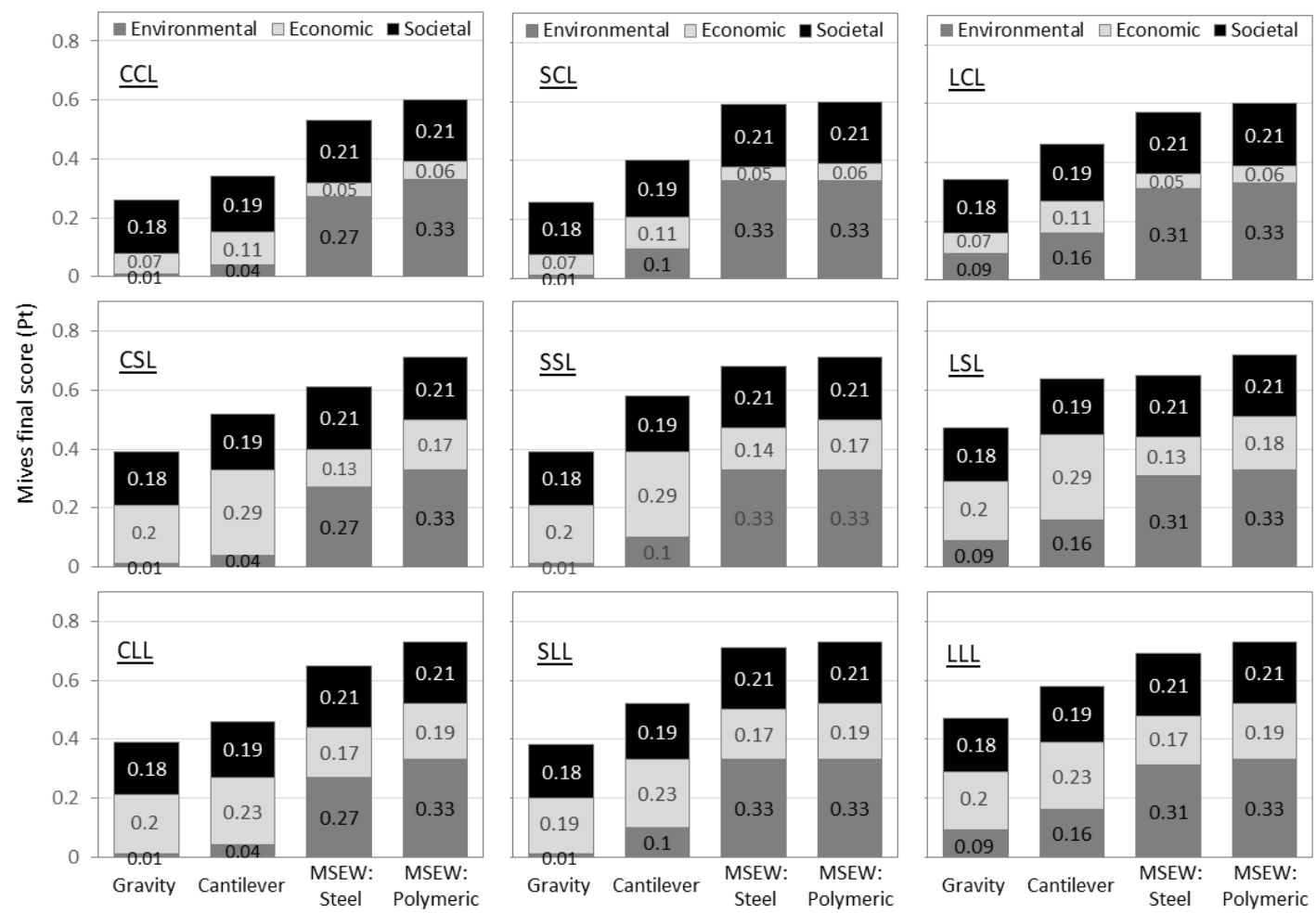

b)
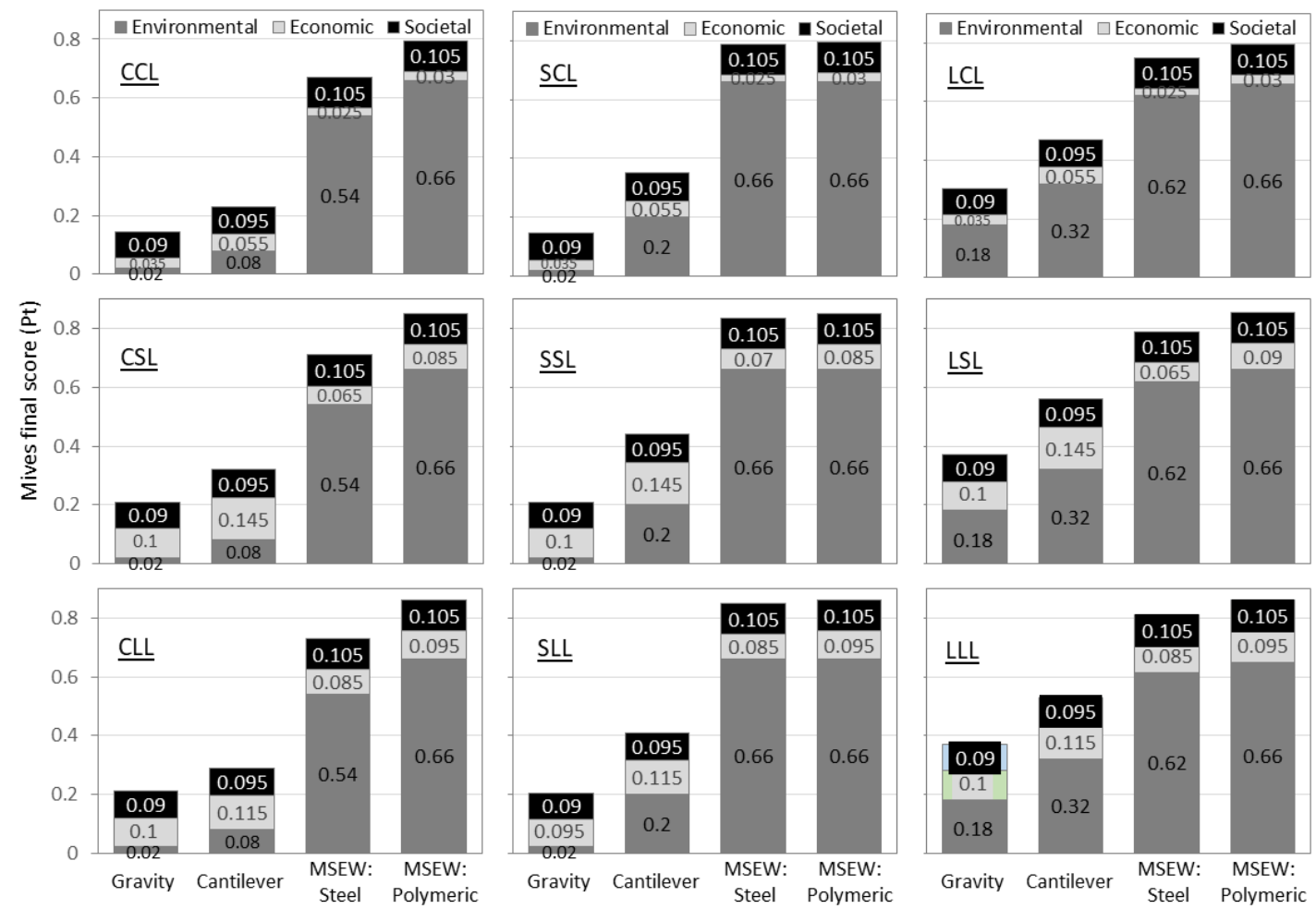

Figure 7. Sustainability results for different weighting scenarios (a) A: 1/3-En. 1/3-Ec. 1/3-So. and (b) B: 2/3-En. 1/6-Ec. 1/6-So. 
a)
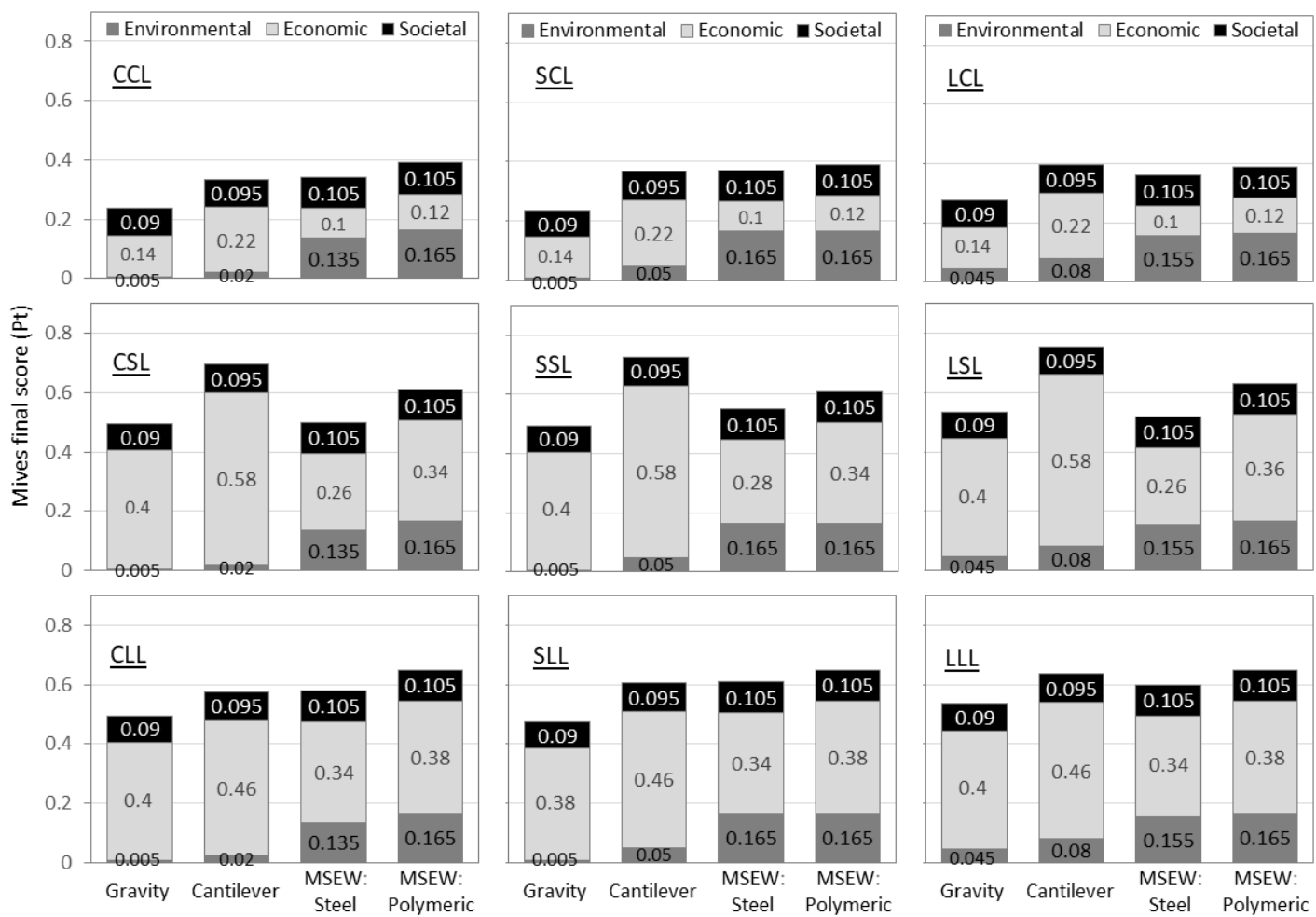

b)
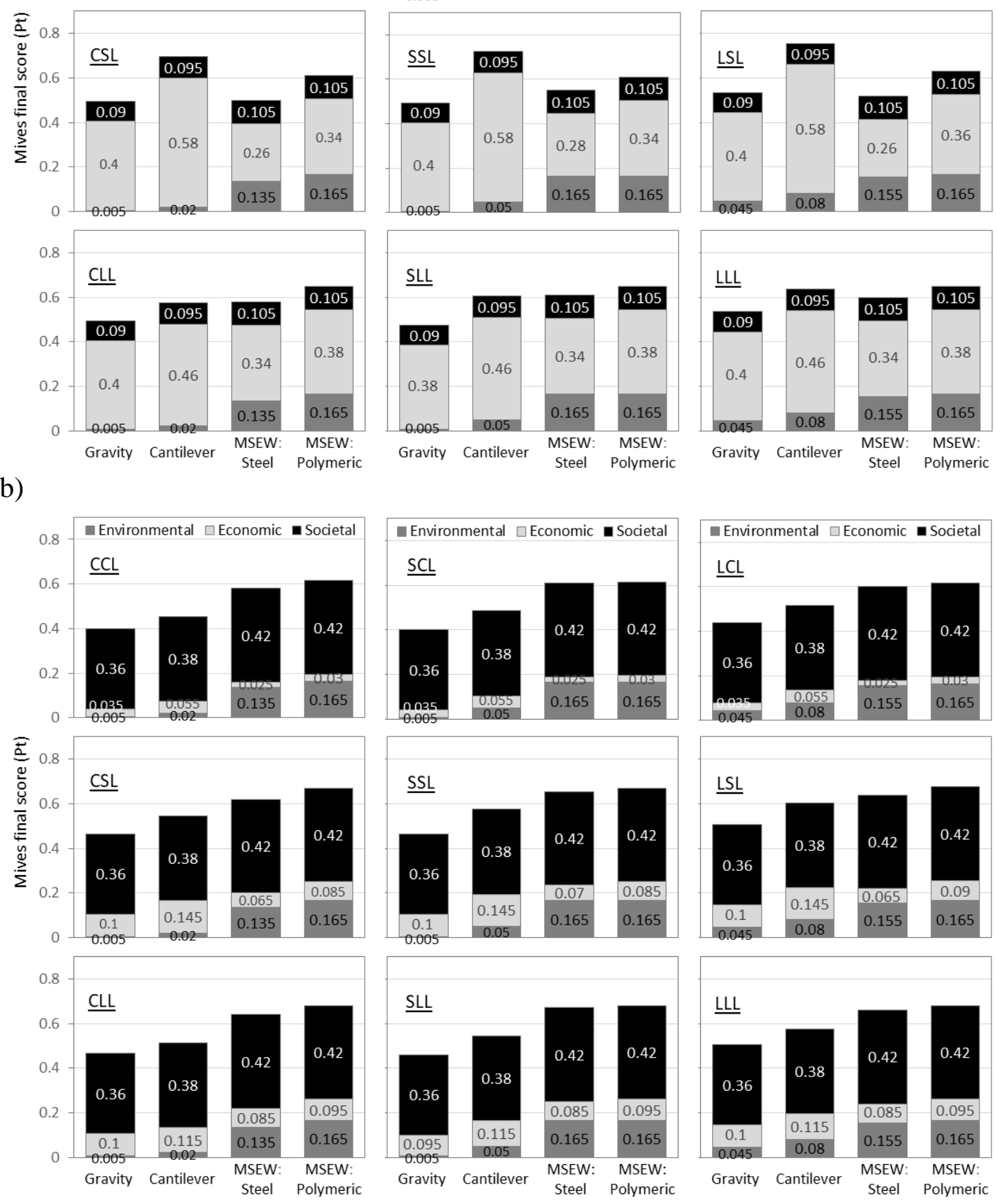

Figure 8. Sustainability results for different weighting scenarios (a) C: 1/6-En. 2/3-Ec. 1/6-So. and (b) D: 1/6-En. 1/6-Ec. 2/3-So. 